\title{
Ciclo de Mejora para la adquisición de autonomía y visión crítica en la construcción arquitectónica
}

\author{
IRENE GARCíA SÁEZ \\ Universidad de Sevilla \\ Escuela Técnica Superior de \\ Arquitectura. Departamento de \\ Construcciones Arquitectónicas I \\ igarcia26@us.es \\ ORCID: https://orcid.org/0000-0002-5316-2834 \\ D.O.I.: http://dx.doi.org/10.12795/JDU.2018.i01.75 \\ Pp.: 1341-1360
}

\section{Resumen}

El paso a la universidad es un cambio en el que los estudiantes pueden sentirse perdidos debido a la gran autonomía que se les concede repentinamente. Por ello se decide aplicar un ciclo de innovación en la práctica docente de la asignatura Construcción 1, del grado de Fundamentos de la Arquitectura, cuya finalidad es orientarlos en la gestión de esa nueva concedida autonomía para alcanzar los objetivos propuestos, desarrollando una visión crítica. La experiencia se centrará en el tema de la envolvente del edificio. El modelo didáctico se basa en la resolución de problemas de forma autónoma, facilitándole al alumnado las herramientas, y empleando un modelo de enseñanza 
teórico-práctico que fomenta su participación, junto a un mapa de contenidos y nuevas herramientas de evaluación. Como resultado, se ha producido una mejor asimilación de contenidos, al tiempo que la implicación de los estudiantes ha aumentado notablemente.

Palabras claves: Construcción 1, Grado en Fundamentos de Arquitectura, Docencia universitaria, Experimentación docente universitaria, Ciclo de mejora.

\section{Contexto}

La innovación se aplica en el tema de Envolvente del edificio: fachadas y cubiertas, de la asignatura Construcción 1, troncal obligatoria del primer cuatrimestre de primer curso del grado de Fundamentos de la Arquitectura. No se puede olvidar que la mayoría de los alumnos no posee ningún conocimiento previo con respecto a la Arquitectura.

De acuerdo con el programa docente de la asignatura, cada tema tiene asociado una práctica que el alumno debe desarrollar en casa y entregarla en la clase siguiente para que sea evaluada y calificada. El conjunto de estos ejercicios tiene un peso del $40 \%$ de la nota final, siendo un $30 \%$ la nota del examen. El resto de la nota lo constituirán trabajos complementarios y la valoración de la asistencia y la participación activa del alumno. Esto se traduce en una asistencia alta, ya que es obligatoria para la evaluación continua.

El grupo está compuesto por 33 alumnos matriculados, de los cuales 25 suelen asistir siempre a las clases, que se imparten los lunes y viernes de 16 a 18. Es un grupo bastante heterogéneo en cuanto al grado de cercanía con los contenidos de la asignatura, puesto que un $20 \%$ de los asistentes habituales son alumnos de segunda matrícula, ya familiarizados con el temario; y el resto son de nuevo ingreso, que afirman no tener conocimientos previos.

El modelo metodológico que se ha seguido tradicionalmente en esta asignatura es el transmisivo. El docente 
ocupa el centro de la clase, impartiendo una clase magistral con una presentación PowerPoint. A partir de ahí, se le exigía al alumno la realización de prácticas, cuya dificultad era notable, debido a la ausencia de tratamiento en las clases de contenidos procedimentales y actitudinales. Por lo general, los resultados obtenidos eran negativos.

Con el Ciclo de Mejora se pretende superar esa formación pobre con respecto a la construcción, facilitándole a los estudiantes las herramientas necesarias para que sean capaces de generar sus propios conocimientos, siendo críticos y autónomos en el desarrollo de su profesión. Así, se organiza el ciclo en cuatro sesiones teórico-prácticas de 2 horas cada una, que son planificadas minuciosamente para el alumnado. La finalidad es conocer y afianzar conceptos fundamentales de la envolvente del edificio y diseñarla en función de la normativa vigente, llegando a representar ese diseño gráficamente, comprendiendo el proceso de construcción y la puesta en obra. Las sesiones, al ser los lunes y los viernes, permiten a los alumnos disponer de tiempo necesario para desarrollar parte de la práctica en casa y a mí evaluar los ejercicios, devolviéndoselos con comentarios valorativos sobre su trabajo.

\section{Diseño previo del Ciclo de Mejora Docente (CMD)}

La problemática objeto de enseñanza en este Ciclo de Mejora es el diseño constructivo de la envolvente del edificio, la piel que protege su interior, y como finalidad formativa su definición mediante una sección constructiva, lo que obliga a saltar de lo teórico a lo procedimental, ya que para representar gráficamente no son suficientes los conceptos teóricos aprendidos en clase. De este modo, se distinguen contenidos conceptuales/ teóricos, procedimentales y actitudinales, teniendo la misma importancia 
tanto los contenidos como sus estructuras y relaciones entre ellos para un aprendizaje de calidad (ver Figura 1).

En cuanto a los conceptos, se tratará en primera instancia la envolvente del edificio, constituida por la fachada y la cubierta, estudiando clasificación, caracterización y puntos singulares. Además, se hablará de las acciones perjudiciales de las que debe proteger dicha envolvente y los requisitos de diseño para el cumplimiento de sus funciones.

Con respecto a los contenidos procedimentales, un pilar fundamental es el cumplimiento de la normativa a la hora de diseñar la envolvente para que cumpla sus funciones. Tampoco podríamos olvidar la realización de controles de calidad ni el seguimiento de la puesta en obra y su ejecución; y, por último, la previsión durante la fase de diseño del futuro mantenimiento y prevención de lesiones debidas a las acciones perjudiciales.

En lo que se refiere a contenidos actitudinales, es necesario mencionar la incorporación de nuevas funciones sostenibles para la envolvente, y de criterios medioambientales y de inclusión social en la fase de diseño. Es importante también el rigor a la hora del seguimiento en obra y el cumplimiento de los controles de calidad para asegurar su seguridad.

Jornadas de Formación e Innovación Docente del Profesorado | № 1 (2018) Esta obra se distribuye con la licencia Creative Commons 


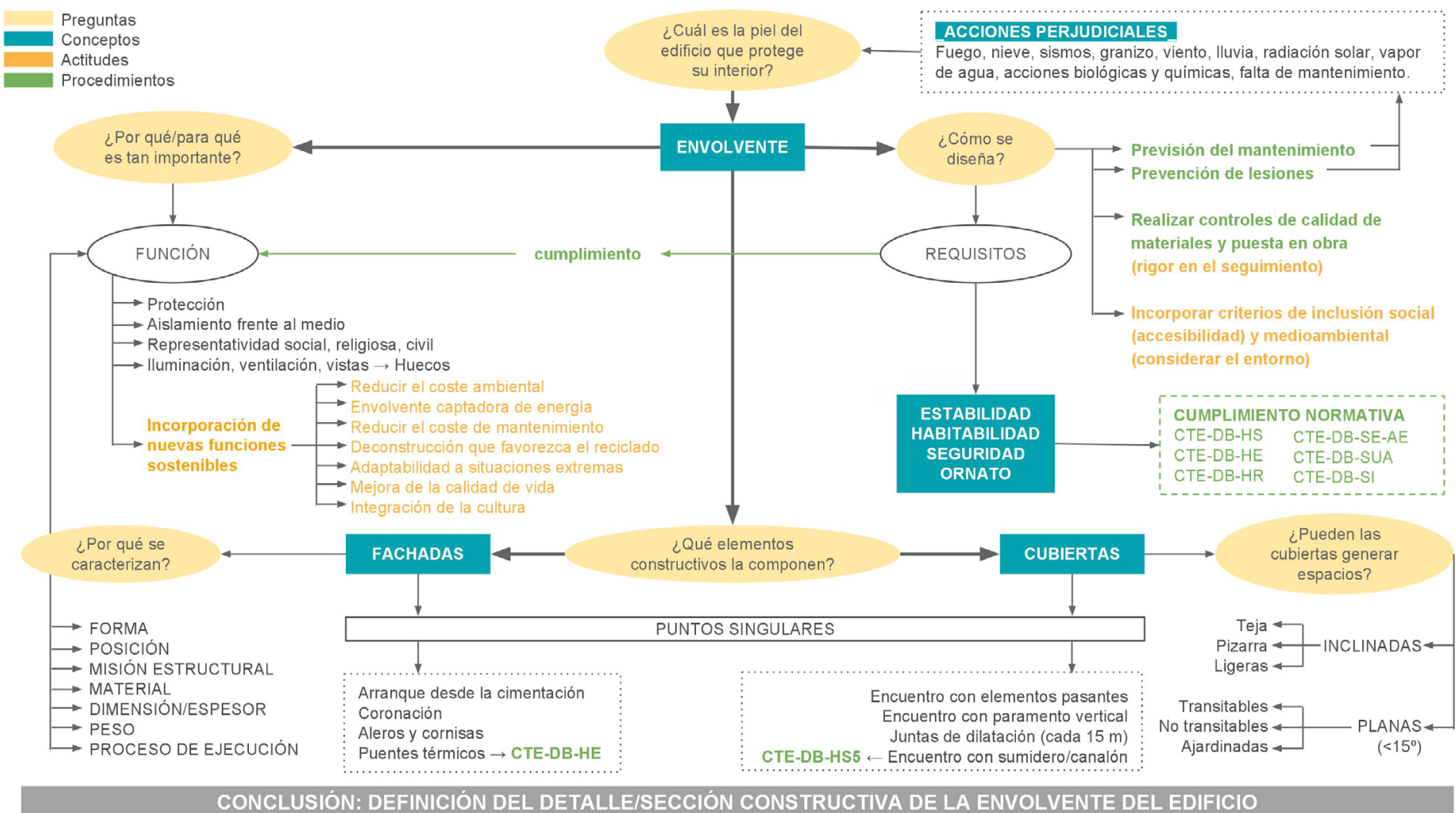

Figura 1. Mapa de contenidos y problemas

Jornadas de Formación e Innovación Docente del Profesorado | № 1 (2018)

CC Esta obra se distribuye con la licencia Creative Commons

(c) (i) $\odot$ Reconocimiento-NoComercial-SinObraDerivada

Internacional (CC BY-NC-ND 4.0.) 


\section{Modelo Metodológico Posible (MMP)}

Partiendo de la premisa de que el contenido de Construcción 1 es muy extenso y rígido, es necesario revisar mi modelo metodológico habitual para adaptarlo en la medida de lo posible a los estudiantes. El reto principal consiste en disminuir mi tiempo de intervención en clase como docente del 100 al 50\% (Finkel, D. 2008, Dar clase con la boca cerrada) y que se equilibre más con el tiempo de trabajo o intervención de los alumnos, haciendo las clases más dinámicas y participativas. La finalidad es alcanzar un entorno agradable para ellos, donde sientan que pueden preguntar dudas y contar con el profesor para aprender (Bain, K. 2007, Lo que hacen los mejores profesores universitarios).

Con esto, mi modelo metodológico trata de avanzar por los contenidos de la asignatura, partiendo de una fase de ideas previas (IP), que me permitirá saber el punto de partida de los alumnos en cada tema nuevo, y cerrando el ciclo con una fase de conclusiones (C), donde se pondrá fin al tema y se hará alusión a esas ideas previas que se comentaron en su momento. Debido a la carga teórica de todos los temas, planteo dividir los contenidos de los temas en dos partes (T1 y T2), aplicando los conceptos en ejercicios prácticos o experiencias (P1 y P2). Se podrá alterar el orden convencional preestablecido de primero teoría y luego práctica, invirtiéndolo cuando se considere oportuno según los contenidos; incluso se podrá intercalar la práctica con breves intervenciones de teoría. Será necesario también incluir una fase de recopilación $(R)$ entre las dos partes, para asentar y reflexionar sobre lo aprendido.

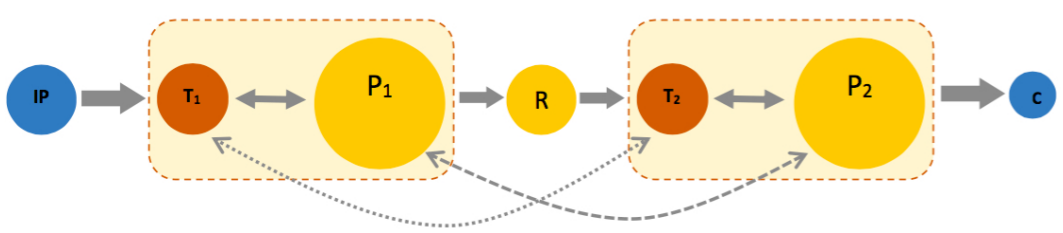

Figura 2. Diagrama del Modelo Metodológico Posible

Jornadas de Formación e Innovación Docente del Profesorado | № 1 (2018) Esta obra se distribuye con la licencia Creative Commons 
La secuencia de actividades programada para cada fase del modelo y partiendo de los problemas seleccionados, se sintetizan en la Tabla 1.

Tabla 1. Secuencia de actividades programada para las sesiones previstas del Ciclo de Mejora

\begin{tabular}{|c|c|c|}
\hline S. & FASE MMP & SECUENCIA DE ACTIVIDADES \\
\hline \multirow{5}{*}{ 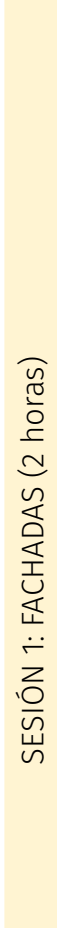 } & \multirow{3}{*}{$\begin{array}{l}\text { Ideas Previas } \\
\text { de los } \\
\text { estudiantes } \\
\text { (30 min) }\end{array}$} & $\begin{array}{l}\text { Encuesta inicial, que estará presente durante todas las } \\
\text { sesiones que abarque el tema, y que una vez finalizado } \\
\text { sean capaces de responder. }\end{array}$ \\
\hline & & $\begin{array}{l}\text { Planteamiento de “las preguntas". Se empezarán a } \\
\text { abarcar las preguntas 1-4 del cuestionario, y seguirán } \\
\text { presentes en el resto de sesiones del ciclo de mejora. }\end{array}$ \\
\hline & & $\begin{array}{l}\text { Presentación del tema que se va a estudiar para con- } \\
\text { textualizar al alumno en el tema que se va a ver. }\end{array}$ \\
\hline & $\begin{array}{l}\text { Práctica } \\
\text { (1 hora) }\end{array}$ & $\begin{array}{l}\text { Ejercicio práctico, manejo de la normativa. Se les en- } \\
\text { tregará a todos los alumnos un ejercicio por escrito que } \\
\text { contendrá preguntas escritas y de representación grá- } \\
\text { fica, y que deberán entregarme al final de clase. En la } \\
\text { siguiente sesión les serán devueltos. No contarán para } \\
\text { nota, pero sí como señal de participación activa en } \\
\text { clase. La hoja contendrá las orientaciones suficientes } \\
\text { para que sean capaces de resolver el problema por gru- } \\
\text { pos de } 4 \text { alumnos. Podrán consultarse entre ellos para } \\
\text { obtener conclusiones. }\end{array}$ \\
\hline & $\begin{array}{l}\text { Teoría } \\
\text { (20 min) }\end{array}$ & $\begin{array}{l}\text { La recomendación del día. Recomendaré un libro re- } \\
\text { lacionado con el tema que se verá en clase y que pue- } \\
\text { dan sacar de la biblioteca para que vayan creando una } \\
\text { buena bibliografía a lo largo del curso y que les sirva de } \\
\text { utilidad para su carrera universitaria y profesional. }\end{array}$ \\
\hline
\end{tabular}

Explicación de contenidos teóricos mínimos para reflexionar sobre el ejercicio anterior hecho. Se resolverán dudas frecuentes entre los grupos de trabajo. Como complemento se les pedirá a los alumnos que se lean en casa un documento.

Jornadas de Formación e Innovación Docente del Profesorado | № 1 (2018) Esta obra se distribuye con la licencia Creative Commons Reconocimiento-NoComercial-SinObraDerivada $\quad 4.0$ Internacional (CC BY-NC-ND 4.0.) 
Recopilación Análisis de imágenes. Se les mostrará a los alumnos (30 min)

\section{Teoría +}

Práctica

$(20 \mathrm{~min}+1 \mathrm{~h})$ en el proyector una serie de fotografías de edificios en construcción o ya construidos que enseñen detalles de fachadas que se hayan visto el día anterior. Se les dejará 10 minutos para que las observen, busquen en los apuntes información sobre lo que se ve y anoten comentarios en una hoja que recogeré. No contarán para nota, pero sí como participación activa.

Puesta en común en voz alta de las imágenes. Solo hablarían los alumnos, a menos que se desvien del tema o se estanquen, momento en el que intervendré para reorientar la conversación sobre las imágenes.

\section{Planteamiento de "las preguntas". Continuaremos ex-} plorando la pregunta 3, a la que le sumaremos la pregunta 5 para dar cierre al apartado de fachadas.

Breve dosis teórica. Debido a la cantidad de puntos singulares que se encuentran en las fachadas, comenzaré con una intervención no demasiado extensa, para proporcionarles los criterios necesarios para que los alumnos puedan solucionar constructivamente esas zonas.

Elaboración de un detalle constructivo de fachada. LOS alumnos comenzarán a desarrollar el ejercicio en clase, teniéndolo que terminar en casa para entregarlo para su evaluación y calificación en la siguiente sesión. Se trata de una práctica individual, en la que tendrán que dibujar a lápiz en un formato A3 distintos detalles constructivos para darle solución a la fachada de su edificio propuesto en clase.

Conclusión

(10 $\mathrm{min})$

Respuesta a "las preguntas" planteada al principio del tema. Actividad de cierre para que la respondan en casa. La respuesta (corta y concisa) me la enviarán por e-mail. 
Ideas Previas Planteamiento de "las preguntas". Se retomarán las

de los

estudiantes

(30 min)

preguntas vistas en la primera sesión (2-4), pero esta

vez nos centraremos exclusivamente en cubiertas.

Ideas previas y puesta en común. Les pido que en un

folio me respondan un par de preguntas muy breves

que les haga pensar, y que a la vez me ayude a introdu-

cir nuevos conceptos necesarios para abordar el tema.

Tras dejarles unos minutos (siempre pueden consultarse entre ellos) ponemos en común respuestas e impresiones. Así me puedo hacer una idea de lo que ya saben y a partir de aquí proceder a presentar el tema.

Práctica Ejercicio práctico, manejo de la normativa. Actividad si-

(1 hora)

milar a la planteada en la sesión1

Experiencia práctica. Visita a la cubierta del centro, donde por grupos de 4 tendrán que identificar los elementos que han leído previamente en la normativa. Deberán sacar fotografías para crear un dosier fotográfico propio.

Teoría La recomendación del día.

(20 min) Explicación de contenidos teóricos mínimos para reflexionar sobre el ejercicio hecho.

Recopilación Análisis de imágenes. Mismo ejercicio que el planteado (30 min)

en la sesión 2, pero sobre cubiertas.

\section{Puesta en común en voz alta de las imágenes.}

Teoría + Planteamiento de "las preguntas". Siguiendo la misma

Práctica metodología, continuaremos con la pregunta 3 y nos

(20 min + 1 abriremos a la 5 para asi cerrar el apartado y el tema.

hora)

Elaboración de un detalle constructivo de cubierta

(práctica asociada al tema). Misma actividad que la propuesta en la sesión 2, pero enfocada a darle solución a la cubierta del mismo edificio.

Breves dosis teóricas intercaladas. Debido a la cantidad de puntos singulares que se encuentran en las cubiertas, realizaré varias intervenciones breves (2 o 3) que intercalaré durante la elaboración del detalle constructivo, para proporcionarles los criterios necesarios para que los alumnos puedan solucionar constructivamente esas zonas conflictivas.

Conclusión

(10 $\mathrm{min})$

Encuesta final, con las mismas preguntas que la inicial, para evaluar el proceso de aprendizaje de los alumnos. 
El cuestionario se limita a las preguntas formuladas en el mapa de contenidos. Son preguntas sencillas, fáciles de comprender para alguien ajeno del mundo de la Arquitectura, de manera que un estudiante de primero, sin ningún tipo de bagaje arquitectónico, podría deducir las respuestas mediante la lógica, la razón y las ideas previas que puedan tener. La comparación de estas respuestas con las que den al final del ciclo, permitirá valorar el aprendizaje experimentado (Porlán, R. 2017, Enseñanza universitaria. Cómo mejorarla).

1. ¿Cuál es la piel del edificio que protege su interior? ¿Cómo se denomina? ¿Qué elementos constructivos la componen?

2. ¿Por qué/para qué es tan importante esa piel? ¿Qué funciones tiene?

3. ¿Cómo se diseña? ¿Qué hay que tener en cuenta? ¿Existe normativa?

4. ¿Por qué se caracterizan? ¿Cómo se podrían clasificar?

5. ¿Cuáles son los puntos singulares o conflictivos de esa piel? ¿Por qué motivos son pu n t o s singulares?

\section{Aplicación del Ciclo de Mejora Docente}

Debido a la extensión del ciclo, en este apartado se expone el relato resumido de las principales actividades desarrolladas, desde el punto de vista de las emociones y sensaciones.

\section{Sesión 1}

Mi CMD comienza con el cuestionario inicial. Tras explicar su finalidad, los alumnos entienden que no serán 
calificados y en ningún momento se quejan ni preguntan. Todos entregan el cuestionario con sus nombres.

Tras esto, el planteamiento de las preguntas me sirvió de introducción del tema, en la que encontré necesario explicar algunos conceptos. Los alumnos intervenían expresando lo que ellos pensaban con respecto a las preguntas planteadas. Mientras yo dibujaba en la pizarra un detalle constructivo que les sirviera para razonar correctamente esa respuesta. Entonces comenzaban a intervenir de nuevo, cambiando sus respuestas. Por último, intervenía yo terminando de matizar lo que habían querido decir y aportando vocabulario técnico.

Tras esto, les entregué un enunciado con instrucciones detalladas para la realización de un ejercicio de manejo de normativa que tendrían que realizar por ellos mismos. Yo caminaba entre los grupos, escuchando y viendo cómo trabajaban. Algunos se ponían nerviosos cuando me acercaba. Cuando tenían dudas levantaban la mano para que les ayudara. Sin embargo, todas las dudas eran resultado de no leer detenidamente.

Los últimos 10 minutos de la sesión me posicioné en el centro de la clase para reforzar contenidos teóricos siguiendo un modelo transmisivo y así cerrar la sesión, dejando que me interrumpieran en caso de tener dudas.

\section{Sesión 2}

La sesión comenzó con el análisis de imágenes, que debían debatir primero en grupos pequeños y más tarde a nivel de clase. Conforme hablaban en voz alta me mantuve al margen, limitándome a dibujar en la pizarra. Finalmente, los alumnos llegaron por ellos mismos a las respuestas, ayudándose de mis aportaciones gráficas. Además de dibujar, planteé un esquema de todos los contenidos que aparecían, de manera que podían tener una visión global del tema. 
Tras la teoría, entramos de lleno en la práctica del tema obligatoria y que se califica. Sin embargo, a los 20 minutos de comenzar a trabajar ya estaban dispersos, de modo que decidí improvisar y pasar a la actividad de cierre del MMP. La última parte de la sesión la dediqué a recapitular y darle un buen cierre a lo visto hasta el momento. Recuperando el esquema que había hecho repasamos las preguntas y vimos si éramos capaces de responderlas. A nivel general me quedé con una buena impresión.

\section{Sesión 3}

Se planteó otra actividad basada en la consulta de forma autónoma de la normativa para la extracción de datos con vistas a la realización de la posterior experiencia práctica: una inspección de la cubierta del centro. Les entrego un guion con instrucciones, se agrupan por equipos y comienzan a trabajar solos. Algunos grupos se dispersan y no consiguen terminar el ejercicio. Tras la recopilación de datos subimos a la cubierta. Los alumnos están entusiasmados con la experiencia, sobre todo por el hecho de que van a ver de primera mano si el edificio se rige por la normativa, y en caso contrario cómo se puede solucionar. Se van deteniendo por las distintas zonas de la cubierta, analizando y fotografiando, reconociendo materiales, etc. De vuelta en el aula, me posiciono en el centro de la clase para asegurarme de que comprenden todos los contenidos vistos en la sesión. Conforme avanzo por las dispositivas planteo en la pizarra un esquema de contenidos para que entiendan las conexiones entre los conceptos. Procuro no impedir darle protagonismo a los estudiantes, que interrumpen mi discurso de manera educada para preguntar dudas. Esto me hace sentir tranquila y satisfecha.

\section{Sesión 4}

Tras una actividad de análisis de imágenes y posterior debate, el resultado no es el esperado. La actividad 
se convierte en una sucesión de turnos para decir las respuestas de cada grupo sin debatir las respuestas de otros compañeros. Para combatirlo, intervengo en contadas ocasiones con preguntas como "¿qué piensas de lo que ha comentado el otro grupo?, ¿estáis de acuerdo? o ¿crees que lo que se ha comentado es correcto?, ¿por qué?".

Como actividad de cierre del ciclo les vuelvo a pasar la encuesta. Parecen sorprendidos y nerviosos. No obstante, sin entretenerse se disponen de manera individual a responder los cuestionarios. Se aprecia una actitud más madura y segura y, tras analizar los resultados, la evolución es notable y muy satisfactoria.

\section{Avances conseguidos y dificultades encontradas}

Tras este Ciclo de Mejora, creo que los alumnos empiezan a ser conscientes del trabajo que deben de ser capaces de llevar a cabo durante su carrera como arquitectos, del grado de dificultad e importancia de resolver los problemas con profesionalidad y responsabilidad, ya que comienzan a conocer las consecuencias que puede tener un mal diseño constructivo por su parte, lo que les hace ser críticos. Como resultado, los alumnos comienzan a ser conscientes de que esta no es una asignatura que se base en memorizar datos, sino en razonar para encontrar una solución constructiva adecuada. Parece ser que comienzan a deducir a partir de lo visto en clase, qué ocurre en ciertas situaciones y cómo diseñar en función de los requisitos que se piden, ayudándose de la normativa para ello.

A lo largo de las 8 horas del CMD ha habido un cambio drástico en la actitud de los alumnos a la hora de enfrentarse a las actividades que tienen que realizar por su cuenta (ya sea de manera individual o por grupos). Al principio, a la más mínima duda que les surgía levantaban la mano para preguntarme y esperaban que con mi respuesta les solucionara la dificultad por completo. En la mayoría de las ocasiones las dudas aparecían por una lectura deficiente del enunciado o de la normativa. Sin embargo, en 
las últimas actividades de manejo de la normativa preguntaban en menos ocasiones y de manera menos impulsiva. Parece que cuando tienen alguna dificultad se detienen a reflexionar sobre ese obstáculo para ver por qué no pueden seguir avanzando, leyendo dos veces antes de acudir a mí a preguntarme. Es de destacar el grado de familiarización con la normativa que han alcanzado, teniendo en cuenta que son alumnos de primero, y la autonomía en el manejo y consulta de ciertos documentos.

También han aparecido dificultades. Una de mis grandes dificultades sigue siendo la falta de tiempo para completar las sesiones tal y como se habían planificado. Cuando se diseñan las clases para que intervengan los estudiantes de forma activa, cualquier actividad consume mucho más tiempo. Además, los periodos de tiempo en los que me sitúo en el centro de la clase para transmitirles ciertos contenidos teóricos son los más difíciles de abordar para mí como docente. A pesar de que intento que sean breves y dinámicos mediante una metodología de clase dialogada, percibo que a veces se aburren y desconectan.

Con respecto a los estudiantes, se identifican una serie de dificultades durante todas las sesiones que en cierta medida han obstaculizado el desarrollo del ciclo respecto a lo que tenía previsto. En primer lugar, carecen de comprensión lectora debido a la falta de atención al leer un texto. Por otro lado, los estudiantes de primer curso no comprenden el concepto de debate ni la finalidad de una actividad de discusión. Se limitan a cederse el turno para expresar lo que ellos piensan, sin escucharse entre ellos ni reflexionar sobre las intervenciones. Cuando les pregunto qué posición tienen con respecto a una opinión no saben qué contestar, porque no saben entablar conexiones entre distintas ideas o puntos de vista. A esto cabría añadir la deficiencia que tienen a la hora de expresarse con respecto al vocabulario técnico visto. Por último, otro gran obstáculo se da cuando deben realizar una actividad por 
su cuenta en un tiempo establecido. En esos momentos aprovechan para preguntarme dudas sobre otros temas, perdiendo tiempo para realizar la actividad. Debido a esto, la mayoría de ellos no son capaces de terminar las actividades, lo que retrasa el ritmo de la sesión. En definitiva, no son conscientes de la importancia de cumplir a tiempo y de saber planificarse. Además, a pesar de que su participación en clase es muy activa, su trabajo en casa no es constante ni continuo, lo que dificulta el enlace entre sesiones. No obstante, todas estas dificultades, en ningún momento constituyen un impedimento para la innovación, siendo en todo caso un incentivo para superarlas en mis próximos ciclos de mejora.

\section{Evaluación del aprendizaje de los estudiantes}

Como herramienta de evaluación de los cambios producidos en los modelos mentales de los estudiantes, nos hemos servido en el ciclo de mejora de un cuestionario (sin peso en la nota final), que se ha pasado al principio y al final del ciclo, y cuyas preguntas (descritas anteriormente) organizaban los bloques fundamentales del mapa de contenidos. Las respuestas se han clasificado en bloques en función del nivel de complejidad alcanzado, acompañadas de sus porcentajes. Se muestran a continuación las respuestas en los cuestionarios inicial y final y sus respectivas escaleras de aprendizaje para las preguntas 2 - ¿Por qué/para qué es tan importante esa piel? (ver Tabla 2 y Figura 3) ¿Cuáles son sus funciones?- y 5 -¿Cuáles crees que pueden ser los puntos más conflictivos de la envolvente? ¿Por qué? (ver Tabla 3 y Figura 4)

Jornadas de Formación e Innovación Docente del Profesorado I № 1 (2018) Esta obra se distribuye con la licencia Creative Commons 
Tabla 2. Respuestas obtenidas en los cuestionarios inicial y final para la pregunta 2

\begin{tabular}{|c|c|c|c|c|c|c|}
\hline \multicolumn{2}{|c|}{ P. } & Escalones & $\begin{array}{l}\text { Cuestionario } \\
\text { inicial }\end{array}$ & $\%$ & $\begin{array}{l}\text { Cuestionario } \\
\text { final }\end{array}$ & $\%$ \\
\hline \multirow[t]{5}{*}{2} & A & $\begin{array}{l}\text { Reconoce múltiples fun- } \\
\text { ciones: habitabilidad } \\
\text { (ventilación, iluminación } \\
\text { y aislamiento), función } \\
\text { estética y delimitación } \\
\text { del perímetro }\end{array}$ & - & 0 & $\begin{array}{l}1,4,6,7,8,9,10 \\
11,14,15,17,20 \\
21,23,25\end{array}$ & 60 \\
\hline & B & $\begin{array}{l}\text { Proporcionar condiciones } \\
\text { de habitabilidad }\end{array}$ & 4,20 & 8,3 & $2,18,19$ & 12 \\
\hline & C & $\begin{array}{l}\text { Aislamiento y protección } \\
\text { térmico y acústico }\end{array}$ & 11,14 & 8,3 & 3 & 4 \\
\hline & D & $\begin{array}{l}\text { Aislamiento/protección } \\
\text { frente a las inclemencias } \\
\text { meteorológicas }\end{array}$ & $\begin{array}{l}1,2,3,5,6,9,10,15 \\
18,19,21,24\end{array}$ & 50 & $12,13,16,22$ & 16 \\
\hline & $E$ & $\begin{array}{l}\text { Proteger/separar el espa- } \\
\text { cio interior del exterior }\end{array}$ & $\begin{array}{l}7,8,12,13,16,17 \\
22,23\end{array}$ & 33,3 & 5,24 & 8 \\
\hline
\end{tabular}

\section{Tabla 3. Respuestas obtenidas en los cuestionarios inicial y final para la pregunta 5}

\begin{tabular}{|c|c|c|c|c|c|c|}
\hline \multicolumn{2}{|c|}{ P. } & \multirow[b]{2}{*}{\begin{tabular}{l}
\multicolumn{1}{c}{ Escalones } \\
Determina cuáles son los \\
principales puntos sin- \\
gulares de la envolvente, \\
razonando el motivo. Es- \\
tablece ejemplos y usa \\
vocabulario apropiado
\end{tabular}} & \multirow{2}{*}{$\frac{\text { Cuestionario inicial }}{1,4,14,18}$} & \multirow{2}{*}{$\frac{\%}{16,5}$} & \multirow{2}{*}{$\begin{array}{l}\text { Cuestionario final } \\
1,2,3,4,8,9,13,18 \\
20,21\end{array}$} & \multirow{2}{*}{$\%$} \\
\hline 5 & A & & & & & \\
\hline & B & $\begin{array}{l}\text { Identifica algunos ejem- } \\
\text { plos y razona su res- } \\
\text { puesta. No emplea } \\
\text { vocabulario específico. }\end{array}$ & $3,5,8,13,22,23,24$ & 29 & $6,10,19,24$ & 16 \\
\hline & C & $\begin{array}{l}\text { Enumera posibles pun- } \\
\text { tos singulares sin justifi- } \\
\text { car su respuesta }\end{array}$ & 2,9 & 8,5 & $\begin{array}{l}11,12,14,15,16 \\
17,22\end{array}$ & 28 \\
\hline & D & $\begin{array}{l}\text { Interpreta libremente } \\
\text { la pregunta y razona su } \\
\text { respuesta }\end{array}$ & $7,10,12,15,20,21$ & 25 & $5,7,23$ & 12 \\
\hline & $\mathrm{E}$ & No contesta & $6,11,16,17,19$ & 21 & 25 & 4 \\
\hline
\end{tabular}

Jornadas de Formación e Innovación Docente del Profesorado I № 1 (2018) Esta obra se distribuye con la licencia Creative Commons Reconocimiento-NoComercial-SinObraDerivada Internacional (CC BY-NC-ND 4.0.) 


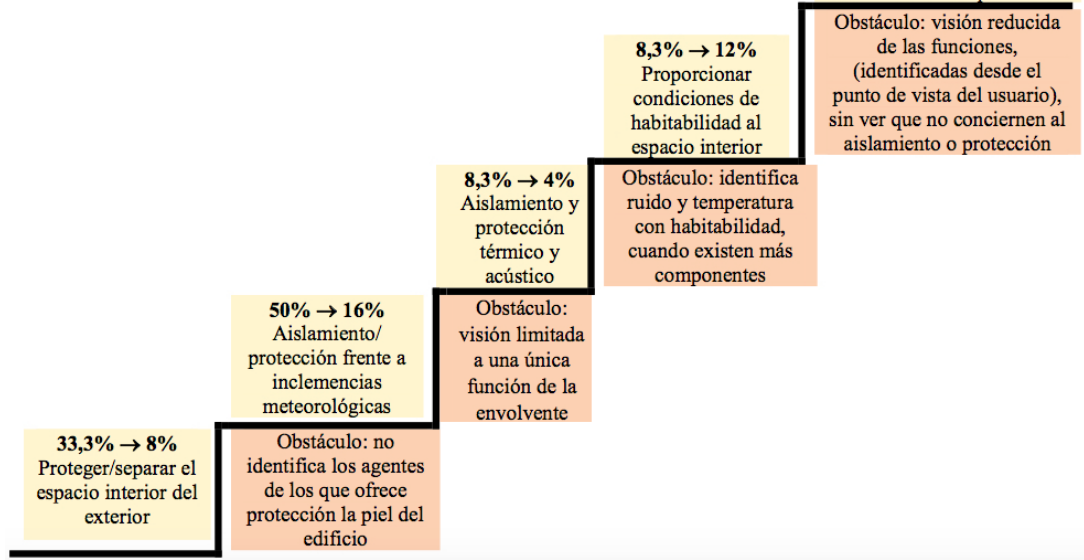

Figura 3. Escalera de aprendizaje de la pregunta 2. Comparativa cuestionario inicial y final

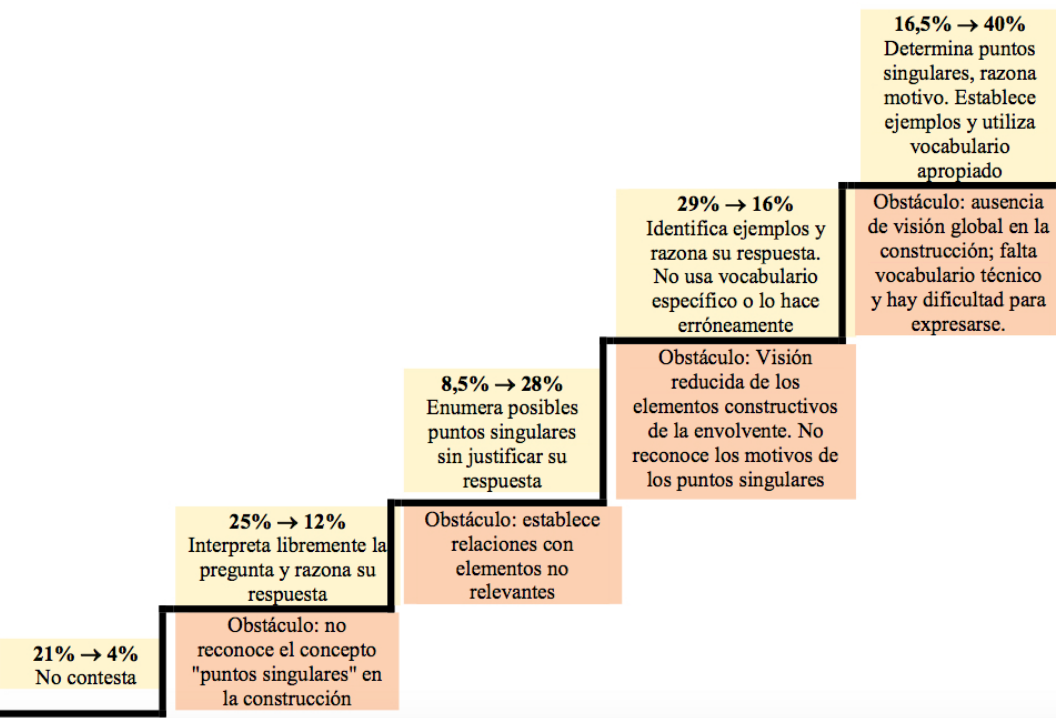

Figura 4. Escalera de aprendizaje de la pregunta 5. Comparativa cuestionario inicial y final

Comparando los modelos iniciales de los estudiantes con los finales se observa un cambio general que se repite en todas las preguntas del cuestionario: se percibe una inversión de la proporción de las respuestas en cada uno de 
los escalones definidos, disminuyendo el porcentaje de alumnos que se encontraban a priori en los primeros escalones y aumentando el número de alumnos que terminan en escalones superiores tras el CMD. Se puede confirmar que en general se ha producido un gran avance en el asimilación de los contenidos por parte del alumno. En torno al 80-90\% han aumentado el nivel de conocimientos relativo al tema de la envolvente del edificio, tras pasar el cuestionario al final del ciclo. Es importante señalar que en ningún momento se les avisó de que al final del tema se les evaluaría de nuevo, de modo que los resultados obtenidos fueron sin haber realizado labores de estudio previas.

Se muestra una ta- Tabla 3. Evaluación individual de los modelos bla que recopila el progreso individual de los modelos de los alumnos que hicieron ambos cuestionarios, pudiéndose corroborar los resultados obtenidos de la evaluación de las escaleras de aprendizaje. Además, se identifican visualmente aquellas preguntas en las que los alumnos han tenido dificultad para alcanzar iniciales y finales de los estudianteslos modelos de los estudiantes

\begin{tabular}{|c|c|c|c|c|c|c|c|c|}
\hline \multirow[t]{2}{*}{ Alumno } & \multicolumn{4}{|c|}{ Bncuesta inicial } & \multicolumn{4}{|c|}{ Encuesta final } \\
\hline & P1 & $\mathbf{P 2}$ & P3 & P5 & P1 & P2 & P3 & P5 \\
\hline Alumno 1 & A & $\mathrm{D}$ & B & A & A & A & B & $\mathrm{A}$ \\
\hline Alumno 2 & B & $\mathrm{D}$ & $\mathrm{B}$ & $\mathrm{C}$ & A & $\mathrm{B}$ & $\mathrm{D}$ & A \\
\hline Alumno 5 & $\mathrm{D}$ & $\mathrm{D}$ & $\mathrm{C}$ & B & $\mathbf{A}$ & $\mathrm{E}$ & $\mathrm{C}$ & D \\
\hline Alumno 6 & B & D & $\mathrm{C}$ & $\mathrm{E}$ & A & A & B & B \\
\hline Alumno 7 & B & $\mathrm{E}$ & $\mathrm{E}$ & $\mathrm{D}$ & A & A & B & D \\
\hline Alumno 8 & B & $\mathrm{E}$ & B & B & $\bar{A}$ & $\mathrm{~A}$ & B & $\mathrm{A}$ \\
\hline Alumno 9 & B & $\mathrm{D}$ & B & $\mathrm{C}$ & A & A & B & A \\
\hline Alumno 10 & B & $\mathrm{D}$ & $\mathrm{D}$ & $\mathrm{D}$ & B & A & B & B \\
\hline Alumno 11 & $\mathrm{C}$ & $\mathrm{C}$ & $\mathrm{C}$ & $\mathrm{E}$ & A & A & B & $\mathrm{C}$ \\
\hline Alumno 12 & $\mathrm{D}$ & $\mathrm{E}$ & B & $\mathrm{D}$ & A & $\mathrm{D}$ & B & $\mathrm{C}$ \\
\hline Alumno 13 & $\mathrm{C}$ & E & B & B & $\mathrm{A}$ & $\mathrm{D}$ & B & A \\
\hline Alumno 15 & B & $\mathrm{D}$ & $\mathrm{E}$ & $\mathrm{D}$ & A & A & B & $\mathrm{C}$ \\
\hline Alumno 16 & $\mathrm{E}$ & $\mathrm{E}$ & B & $\mathrm{E}$ & A & D & D & $\mathrm{C}$ \\
\hline Alumno 17 & E & E & $\mathrm{C}$ & E & A & A & B & $\mathrm{C}$ \\
\hline Alumno 18 & A & $\mathrm{D}$ & B & A & A & B & B & A \\
\hline Alumno 19 & B & $\mathrm{D}$ & B & E & A & B & B & B \\
\hline Alumno 20 & $\mathrm{C}$ & B & $\mathrm{C}$ & $\mathrm{D}$ & $\mathrm{A}$ & $\bar{A}$ & B & $\mathrm{A}$ \\
\hline Alumno 21 & $\mathrm{C}$ & D & B & D & A & A & B & A \\
\hline Alumno 22 & $\mathrm{C}$ & $\mathrm{E}$ & $\mathrm{D}$ & B & A & $\mathrm{D}$ & A & $\mathrm{C}$ \\
\hline Alumno 23 & B & $\mathrm{E}$ & $\mathrm{C}$ & B & A & A & D & D \\
\hline Alumno 24 & B & D & $\mathrm{D}$ & B & A & $\mathrm{E}$ & A & B \\
\hline
\end{tabular}
un nivel de respuesta más complejo y acertado, como en las preguntas 3 y 5 . Esto se debe a la dificultad de los contenidos y sus relaciones, que requieren una visión global de la construcción. 


\section{Evaluación del Ciclo de Mejora Docente}

Tras la aplicación del Ciclo de Mejora y de la experiencia positiva obtenida, debido al amplio índice de asistencia y participación y los resultados de los cuestionarios, hay una serie de cambios que considero fundamentales introducir en mi práctica docente habitual, y que se han convertido ya en mis principios didácticos. Se podrían clasificar en cuatro bloques:

a) El aprendizaje de los estudiantes. Se comenzarán las clases con una actividad que favorezca la interacción entre los estudiantes partiendo de sus conocimientos previos. Además, se planeará el curso/las clases hacia atrás, teniendo en cuenta qué tienen que ser capaces de hacer los estudiantes al final del semestre/al final de cada tema.

b) Los contenidos de enseñanza. Se enseñarán en la medida de lo posible los contenidos teóricos desde un punto de vista más procedimental y actitudinal, otorgándoles igual importancia tanto a los conceptos como a las relaciones y conexiones entre ellos. Se basarán los contenidos de la asignatura en el análisis de material gráfico, intentando llevar los contenidos fuera del aula, animándolos a aprender de cualquier situación.

c) La metodología. Se establecerá una metodología docente dialogada, basada en sesiones teórico-prácticas, en las que se planificarán actividades de corta duración (15 minutos), que tengan que desarrollar de manera autónoma y en las que deban mantener contacto directo con el material con el que vayan a trabajar en su vida profesional. Se mostrarán planos de estudios de arquitectura, imágenes reales y artículos, que pongan en evidencia la relación directa entre lo 
aprendido y su aplicación real en la profesión, y se realizarán experiencias, como visitas de inspección de obra, en las que el alumno sea protagonista y responsable, enfocándolas desde lo procedimental y actitudinal (Finkel, D. 2008, Dar clase con la boca cerrada).

d) La evaluación. Por un lado del profesor, realizándose evaluaciones intermedias y finales para comprobar si la docencia es efectiva, y en caso contrario cambiar aquellas deficiencias. Por otro lado, se planteará evaluar a los estudiantes planteando una pregunta breve que respondan de manera individual al final de clase y que sirva como reflexión de lo que aprendido en la sesión, sin que cuente para nota.

\section{Referencias bibliográficas}

Bain, K. (2007). Lo que hacen los mejores profesores universitarios. Valencia: Publicaciones de la Universidad de Valencia.

Finkel, D. (2008). Dar clase con la boca cerrada. Valencia: Públicaciones de la Universidad de Valencia.

Porlán, R. Coord. (2017). Enseñanza universitaria. Cómo mejorarla. Madrid: Morata.

Jornadas de Formación e Innovación Docente del Profesorado | № 1 (2018) Esta obra se distribuye con la licencia Creative Commons 